\title{
Knowledge and utilization of computer among health workers in Addis Ababa hospitals, Ethiopia: computer literacy in the health sector
}

\author{
Ebrahim Mohammed ${ }^{1 \dagger}$, Gashaw Andargie ${ }^{2 \dagger}$, Solomon Meseret ${ }^{2 \dagger}$ and Eshetu Girma ${ }^{3 *}$
}

\begin{abstract}
Background: Incorporation of information technology advancements in healthcare has gained wide acceptance in the last two decades. Developed countries have successfully incorporated information technology advancements in their healthcare system thus, improving healthcare. However, only a limited application of information technology advancements is seen in developing countries in their healthcare system. Hence, this study was aimed at assessing knowledge and utilization of computer among health workers in Addis Ababa hospitals.
\end{abstract}

Methods: A quantitative cross-sectional study was conducted among 304 health workers who were selected using stratified sampling technique from all governmental hospitals in Addis Ababa. Data was collected from April 15 to April 30, 2010 using a structured, self-administered, and pre-tested questionnaire from five government hospitals in Addis Ababa. The data was entered into Epi Info version 3.5.1 and exported to SPSS version 16. Analysis was done using multinomial logistic regression technique.

Results: A total of 270 participants, age ranging from 21 to 60 years responded to the survey (88.8\% response rate). A total of 91 (33.7\%) respondents had an adequate knowledge of computers while 108 (40.0\%) had fair knowledge and $71(26.3 \%)$ of the respondents showed inadequate knowledge. A total of 38(14.1\%) were adequately utilizing computers, 14(5.2\%) demonstrated average or fair utilization and majority of the respondents $218(80.7 \%)$ inadequately utilized computers. Significant predictor variables were average monthly income, job satisfaction index and own computer possession.

Conclusions: Computer knowledge and utilization habit of health workers were found to be very low. Increasing accessibility to computers and delivering training on the use of computers for workers will increases the knowledge and utilization of computers. This will facilitate the rate of diffusion of the technology to the health sector. Hence, programs targeted at enhancing knowledge and skill of computer use and increasing access to computer should be designed. The association between computer knowledge/skill and health care delivery competence should be studied.

Keywords: Computer, Knowledge, Utilization, Health care, Health workers, Computer literacy

\section{Background}

Since the advent of computers, there has been significant interests in the collection, storage, retrieval, and analysis of a wide range of information in all spheres of socioeconomic development endeavor [1]. In the health sector, advances in information and computer technology in the last quarter of the twentieth century has led to the ability

\footnotetext{
* Correspondence: grm_sht@yahoo.com

${ }^{\dagger}$ Equal contributors

${ }^{3}$ Department of Health Education and Behavioral Sciences, Jimma University, Jimma, Ethiopia

Full list of author information is available at the end of the article
}

to more accurately profile individual health risk, to understand better basic physiologic and pathologic processes and diagnosis through new imaging and scanning technologies. Such technological development, however, demands an increased responsibility of practitioners, managers, and policy-makers to assess appropriateness of new technologies [2].

Information technology is at the heart of modern healthcare systems and services and can distribute information world-wide. National and international e-health initiatives are challenged by deep-rooted problems and

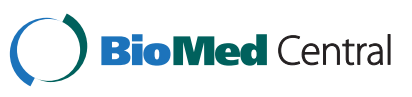


lack of infrastructures like access to computers. Many remote villages that lack easy access to hospitals and advanced medical facilities are now being educated through telemedicine and digitalized health information. This initiative is helping millions of citizens improve their daily lives [3].

A survey in Ethiopia indicated that $46 \%$ of the schools/colleges, $41 \%$ of the public institutions use computers for administration. Among different institutions, only $28 \%$ of the health facilities which was very low as compared to other institution used computer for different purposes [4]. In contrary, there was high knowledge and use of computers among dental sciences faculty, at the University of Lagos, Nigeria [5].

A study in a Nigerian University Teaching hospital in 2004 found that $18.9 \%$ of health professionals demonstrated a good knowledge of computers while $58.8 \%$ had average knowledge. Only $22.3 \%$ showed poor knowledge. Among these study participants, only $39.9 \%$ demonstrated good utilization habits, while in $33.8 \%$ utilization habits were average [6]. Another study conducted among clinical year medical students of Ahmadu Bello University, in Nigeria showed that $50.6 \%$ of the participants had knowledge about computer technology and its use while $49.4 \%$ did not know much about computers and their use [7]. A survey conducted in northern Ethiopia showed that computer illiteracy rate was $89.41 \%$. From the overall workforce surveyed in Ethiopia, computer trained workforce accounted only for $0.17 \%$ [8].

Previous studies identified the following as factors affecting computer utilization: computers, training on the use of computers and age [1,6,8-11].

Ethiopia is in a position to implement the Health management information system (HMIS). This involves computer application starting from entering patient records to the use telemedicine to educate healthcare providers on the cases that are beyond the capacity of Ethiopian Hospitals. Little is known about the knowledge and utilization patterns of computer, and there are no published reports on the knowledge, utilization and factors affecting utilization of computer among health workers in Ethiopia. To fill the gap, it was important to assess knowledge of health workers that might predict their acceptance and mode of use of computer systems. These include how much they know about computers. How many health workers currently use computers and factor affecting utilization habit of computer?

\section{Methods}

Institution based quantitative cross-sectional study design was used to assess knowledge, utilization and factors affecting knowledge and utilization of computer among health workers. The study was conducted in Addis Ababa, the capital city of Ethiopia. It is the largest city in Ethiopia, with a population of $3,384,569$ according to the 2008 population census [12]. There are five governmental hospitals which are governed by Addis Ababa administrative health bureau; namely, Ras Desta, Gandi, Minilik, Yekatit 12, and Zewditu Hospital. The study was carried out from April to June, 2010.

Sample of 304 health workers in the five hospitals were included in the study. Only those health workers who have worked in the study area at least for 6 months were included in the study. The sample size was calculated using single population proportion formula by assuming proportion of people with adequate knowledge of computer 0.59 [6] , 95\% confidence interval, 0.05 margin of error and 10\% contingency for non-response. Final correction formula was also used. The study participants were selected using simple random sampling technique with proportional allocation among the five hospitals. There were a total of 1072 total health workers in the five hospitals. Based on the proportion of health workers in each hospital, 33 health workers from Rass Desta, 35 from Gandi, 70 from Minilik, 77 from Yekatit twelve and 55 from Zewditu were included. Lists of health workers were prepared for each hospital as sampling frames. A pretested self administered questionnaire was used to collect data on socio-demographic characteristics, computer knowledge and utilization of health workers was adopted from previous study [9]. The questionnaire was prepared in English language. The data collection was facilitated by 5 information technology diploma holders and supervision was done by the principal investigator.

In this study health workers were those employees with at least a diploma certificate on health profession. Computer knowledge was defined as a basic understanding of computer concepts. It involves knowing hard and soft ware, what computer virus mean how to manage files, and knowing how to use basic computer applications like computer network, information highway and internet. A total of 20 questions were used to assess the knowledge of computer. Based on the cut of value from the Nigerian study in 2004 on the same topic it was classified as follows for both knowledge and utilization of computer among health workers. (1) Adequate computer knowledge: those study subjects who scored greater than $80 \%$ of knowledge questions, (2) Fair computer knowledge: those study subjects who scored $60 \%$ to $79 \%$ of knowledge questions and (3) inadequate computer knowledge: those study subjects who scored less than $60 \%$ of knowledge questions. Utilization of computer is the basic skill and use of computer and internet, manage files, storing, retrieve, analyzing and presenting the data on hand. A total of 15 questions were used to assess health worker's computer utilization habits. (1) Adequate computer utilization: those study subjects who scored greater than $60 \%$ of utilization questions). (2) 
Table 1 Socio-demographic characteristics of respondents in Addis Ababa administrative hospitals Addis Ababa Ethiopia, June 2010

\begin{tabular}{|c|c|c|c|c|c|c|}
\hline \multirow[t]{2}{*}{ Variables } & \multicolumn{5}{|c|}{ Hospitals } & \multirow{2}{*}{$\begin{array}{l}\text { Total, } \\
\mathrm{n}=\mathbf{2 7 0}(\%\end{array}$} \\
\hline & Ras Desta, $n=33(\%)$ & Gandi, $n=35(\%)$ & Zewditu, n=55(\%) & Yekatit 12, n=77(\%) & Minilik, n=70(\%) & \\
\hline \multicolumn{7}{|l|}{ Sex } \\
\hline Females & $15(5.6)$ & $28(10.4)$ & $39(14.4)$ & $44(16.3)$ & $23(8.5)$ & 149(55.2) \\
\hline Males & $18(6.7)$ & $27(10.0)$ & $31(11.5)$ & $33(12.2)$ & $12(4.4)$ & $121(44.8)$ \\
\hline \multicolumn{7}{|l|}{ Age } \\
\hline$\leq 25$ & $4(1.5)$ & $8(3.0)$ & $15(5.6)$ & $21(7.8)$ & $10(3.7)$ & $58(21.5)$ \\
\hline $26-29$ & $13(4.8)$ & $10(3.7)$ & $25(9.3)$ & $18(6.7)$ & $15(5.6)$ & $81(30.0)$ \\
\hline$\geq 30$ & $16(5.9)$ & $17(6.3)$ & $30(11.1)$ & $38(14.1)$ & $30(11.1)$ & $131(48.5)$ \\
\hline \multicolumn{7}{|l|}{ Marital status } \\
\hline Ever married & $18(6.7)$ & $19(7.0)$ & $37(13.7)$ & 49(18.1) & $33(12.2)$ & 156(57.8) \\
\hline Never married & 15(5.6) & $16(5.9)$ & $33(12.2)$ & $28(10.4)$ & $22(8.1)$ & $114(42.2)$ \\
\hline \multicolumn{7}{|l|}{ Religion } \\
\hline Orthodox & 15(5.6) & $16(5.9)$ & $50(18.5)$ & 49(18.1) & 28(10.4) & 158(58.5) \\
\hline Protestant & $10(3.7)$ & $14(5.2)$ & $12(4.4)$ & $20(7.4)$ & $16(5.9)$ & $72(26.7)$ \\
\hline Muslim & $8(3.0)$ & $5(1.9)$ & $8(3.0)$ & $8(3.0)$ & $11(4.1)$ & $40(14.8)$ \\
\hline \multicolumn{7}{|l|}{ Monthly income } \\
\hline Low & $16(5.9)$ & $23(8.5)$ & 29(10.7) & 36(13.3) & $38(14.1)$ & $142(52.6)$ \\
\hline High & $17(6.3)$ & $12(4.4)$ & $26(9.6)$ & $41(15.2)$ & $32(11.9)$ & $128(47.4)$ \\
\hline \multicolumn{7}{|l|}{ Field of study } \\
\hline Nurse & $8(3.0)$ & $22(8.1)$ & $39(14.4)$ & $47(17.4)$ & 24(8.9) & 140(51.9) \\
\hline Lab and pharmacy & $13(4.8)$ & $8(3.0)$ & $10(3.7)$ & $12(4.4)$ & $17(6.3)$ & $60(22.2)$ \\
\hline $\mathrm{MD}$ and $\mathrm{HO}$ & $6(2.2)$ & $3(1.1)$ & $13(4.8)$ & $9(3.3)$ & $6(2.2)$ & $37(13.7)$ \\
\hline Others & $6(2.2)$ & $2(.7)$ & $8(3.0)$ & $9(3.3)$ & $8(3.0)$ & $33(12.2)$ \\
\hline \multicolumn{7}{|l|}{ Educational level } \\
\hline BSc and diploma & $28(10.4)$ & $32(11.9)$ & $50(18.5)$ & $72(26.7)$ & $59(21.9)$ & $241(89.3)$ \\
\hline Above BSc & $5(1.9)$ & $3(1.1)$ & $5(1.9)$ & $5(1.9)$ & $11(4.1)$ & 29(10.7) \\
\hline
\end{tabular}

MD Medical doctor; $\mathrm{HO}$ Health officer \& others include: environmental health, dentistry, physiotherapy \& radiography.

Table 2 Job satisfaction, training received and computer possession among the respondents in Addis Ababa administrative hospitals Addis Ababa, Ethiopia, June 2010

\begin{tabular}{|c|c|c|c|c|c|c|}
\hline \multirow[t]{2}{*}{ Variables } & \multicolumn{5}{|c|}{ Hospitals } & \multirow[t]{2}{*}{ Total $(\%$} \\
\hline & Ras Desta(\%) & Gandi (\%) & Zewditu (\%) & Yekatit 12 (\%) & Minilik (\%) & \\
\hline \multicolumn{7}{|l|}{ Job satisfaction } \\
\hline Satisfied & $11(4.1)$ & $20(7.4)$ & $32(11.9)$ & $37(13.7)$ & $33(12.2)$ & 133(49.3) \\
\hline Poorly satisfied & $17(6.3)$ & $9(3.3)$ & 28(10.4) & $27(10.0)$ & $12(4.4)$ & 93(34.4) \\
\hline Very satisfied & $5(1.9)$ & $6(2.2)$ & $10(3.7)$ & $13(4.8)$ & $10(3.7)$ & $44(16.3)$ \\
\hline \multicolumn{7}{|c|}{ computer training } \\
\hline Trained & $20(7.4)$ & $20(7.4)$ & $30(11.1)$ & $41(15.2)$ & $23(8.5)$ & 134(49.6) \\
\hline Not trained & $13(4.8)$ & 15(5.6) & 40(14.8) & $36(13.3)$ & $32(11.9)$ & $136(50.4)$ \\
\hline \multicolumn{7}{|c|}{ Owned computer } \\
\hline Owed & $11(4.1)$ & $10(3.7)$ & 15(5.6) & $21(7.8)$ & $10(3.7)$ & $67(24.8)$ \\
\hline Not & $22(8.1)$ & $25(9.3)$ & $55(20.4)$ & $56(20.7)$ & $45(16.7)$ & 203(75.2) \\
\hline
\end{tabular}


Table 3 factors associated with adequate knowledge of computer among health workers at Addis Ababa administrative hospitals Ethiopia, June 2010

\begin{tabular}{|c|c|c|c|c|}
\hline \multirow[t]{2}{*}{ Predictor variable } & \multicolumn{2}{|c|}{ Knowledge } & \multirow[t]{2}{*}{ COR $(95 \% \mathrm{Cl})$} & \multirow[t]{2}{*}{ AOR $(95 \% \mathrm{Cl})$} \\
\hline & Adequate & Inadequate & & \\
\hline \multicolumn{5}{|l|}{ Sex } \\
\hline Male & 49 & 26 & $2.02(1.02,3.81)$ & $1.51(0.66,3.43)$ \\
\hline Female & 42 & 45 & 1.00 & 1.00 \\
\hline \multicolumn{5}{|l|}{ Age } \\
\hline$\leq 25$ & 27 & 11 & $3.66(1.59,8.35)$ & $2.30(0.69,7.70)$ \\
\hline $26-29$ & 31 & 11 & $4.19(1.85,9.48)$ & $2.81(0.99,7.97)$ \\
\hline$\geq 30$ & 33 & 49 & 1.00 & 1.00 \\
\hline \multicolumn{5}{|l|}{ Marital status } \\
\hline Never married & 50 & 18 & $3.59(1.83,7.06)$ & $3.05(1.11,8.39)^{*}$ \\
\hline Ever married & 41 & 53 & 1.00 & 1.00 \\
\hline \multicolumn{5}{|l|}{ Monthly income } \\
\hline Low & 50 & 18 & $0.11(0.05,0.22)$ & $0.26(0.11,0.65)^{*}$ \\
\hline High & 41 & 53 & 1.00 & 1.00 \\
\hline \multicolumn{5}{|l|}{ Job satisfaction } \\
\hline Very satisfied & 17 & 7 & $2.80(1.01,7.81)$ & $1.98(0.59,6.67)$ \\
\hline Satisfied & 48 & 34 & $1.63(0.82,3.23)$ & $2.67(1.12,6.37)^{*}$ \\
\hline Unsatisfied & 26 & 30 & 1.00 & 1.00 \\
\hline \multicolumn{5}{|l|}{ Field of study } \\
\hline $\mathrm{MD} \& \mathrm{HO}$ & 22 & 2 & $5.92(1.07,32.90)$ & $3.24(0.20,51.41)$ \\
\hline Nurses & 30 & 50 & $0.32(0.12,0.90)$ & $0.52(0.15,1.80)$ \\
\hline Laboratory \& pharmacy & 26 & 12 & $1.17(0.37,3.67)$ & $0.89(0.23,3.40)$ \\
\hline Others & 13 & 7 & 1.00 & 1.00 \\
\hline \multicolumn{5}{|l|}{ Education } \\
\hline Greater than degree & 20 & 2 & $9.72(2.19,43.16)$ & $0.75(0.05,11.19)$ \\
\hline Degree and diploma & 71 & 69 & 1.00 & 1.00 \\
\hline \multicolumn{5}{|l|}{ Computer training } \\
\hline Trained & 56 & 22 & $3.56(1.85,6.87)$ & $2.81(1.22,6.43)^{*}$ \\
\hline Not & 35 & 49 & 1.00 & 1.00 \\
\hline \multicolumn{5}{|l|}{ Owned computer } \\
\hline Owned & 41 & 6 & $8.88(3.50,22.58)$ & $6.35(2.00,20.18)^{*}$ \\
\hline Not & 50 & 65 & 1.00 & 1.00 \\
\hline
\end{tabular}

MD Medical doctor, $\mathrm{HO}$ Health officer and others refers to environmental health, dentistry, radiography and physiotherapy.

* Indicates significant at $\mathrm{p}<0.05$.

Fair computer utilization: those study subjects who scored $50 \%$ to $59 \%$ of utilization questions. (3) Inadequate computer utilization: those study subjects who scored less than $50 \%$ of utilization question.

Data was entered using Epi Info for double data entry. Then it was exported to SPSS package version 16 for analysis. Frequencies and cross tabulations were used for the descriptive analysis of the data. Associations between participant's characteristics and knowledge and utilization of computer were analyzed using multinomial logistic regression. Ethical clearance committee of the University of Gondar College of Medicine and Health science through School of Public Health approved this study. Data was collected after getting permission and clearance from ethical clearance committee of Addis Ababa administrative health bureau Written consent was obtained from each respondent.

\section{Results}

Socio- demographic characteristics

The response rate was $270(88.8 \%)$. Female to male ratio was 1.23: 1 (149 females and 121 males). The median age 
of the respondents was 29 years. Never married and ever married study participants were 114(42.2\%) and 156 (57.8\%) respectively. One hundred and fifty eight (58.5\%) of the respondents were Orthodox. One hundred and forty two $(52.6 \%)$ of them were paid less than or equal to 1500 ETHB (1 USD = 18.4 ETHB) monthly salary. Regarding job satisfaction of the respondents, 49.4\%.of respondents were satisfied with their work. One hundred and forty (51.9\%) of the respondents were nurses, majority of whom have either a bachelors degree or a diploma (89.3\%) (Table 1).

\section{Computer possession, training and job satisfaction}

Hundred thirty four (49.6\%) respondents had computer training before. Majority of the health workers 203 (75.2\%) had no own computer. A total of 133 (49.3\%) them were satisfied with their work (Table 2).

\section{Knowledge on computer}

A total of 91(33.7\%) respondents demonstrated adequate knowledge of computers, $108(40.0 \%)$ of them had fair knowledge while 71 (26.3\%) showed inadequate knowledge. Results from the multinomial logistic regression analysis indicated that, those who never married were more knowledgeable [AOR- 3.05, 95\% CI $(1.11,8.39)$ ] than ever married individuals. People with less income were less knowledgeable [AOR- 0.26, 95\% CI $(0.11,0.65)$ ]. Regarding the job satisfaction of the respondents, respondents in the satisfied category had statistically significant higher knowledge (AOR- 2.67, 95\% CI $(1.12,6.37)]$. People with training on computers were more likely to be knowledgeable [AOR- 2.81, 95\% CI $(1.22,6.43)]$ than without training Computer possession was also statistically associated (AOR- 6.35, 95\% CI $(2.00,20.18)]$ with having high knowledge on computers (Table 3). Those people whose ages were between 25-29 years were more likely [AOR- 2.54, 95\% CI $(1.04,6.22)]$ to have fair knowledge than people with more than 30 years age. And respondents with less income were less likely [AOR- 0.34, 95\% CI $(0.15,0.77)]$ to have fair knowledge than high income groups (Table 4).

\section{Utilization of computer}

A total of $38(14.1 \%)$ had adequately utilized computer, 14(5.2\%) demonstrated average or fair utilization and majority of the respondents $218(80.7 \%)$ inadequately utilized computer. Males than female [AOR- 3.06, 95\% CI $(1.13,8.27)]$, those who were satisfied with their job than not satisfied with their job [AOR- 3.41, 95\% CI (1.08, 10.76)] and who owned computer than not owned personal computers were more likely to adequately utilize computer. Respondents with less income and nurses were less likely to utilize computers adequately (Table 5). People with less income were also less likely [AOR-0.11, 95\% CI $(0.02,0.56)]$ to fairly utilize computers than high income groups (Table 6).

\section{Discussion}

In this study, knowledge was very low compared to findings in previous studies $[9,10]$. These may be due to socio-economic differences and diffusion rate of technology among those study subjects. However, findings in this study showed higher knowledge of computer than a study in Nigerian University teaching hospital staffs $[6,7]$. These differences might be attributed the time gap between the two studies conducted.

Table 4 Factors associated with fair knowledge of computer among health workers at Addis Ababa administrative hospitals Ethiopia, June 2010

\begin{tabular}{|c|c|c|c|c|}
\hline \multirow[t]{2}{*}{ Variables } & \multicolumn{2}{|c|}{ Knowledge } & \multirow[t]{2}{*}{ COR $(95 \% \mathrm{Cl})$} & \multirow[t]{2}{*}{ AOR $(95 \% \mathrm{Cl})$} \\
\hline & Fair & Inadequate & & \\
\hline \multicolumn{5}{|l|}{ Age } \\
\hline$\leq 25$ & 20 & 11 & $1.82(0.79,4.19)$ & $1.05(0.35,3.19)$ \\
\hline $26-29$ & 39 & 11 & $3.55(1.63,7.72)$ & $2.54(1.04,6.22)^{*}$ \\
\hline$\geq 30$ & 49 & 49 & 1.00 & 1.00 \\
\hline \multicolumn{5}{|l|}{ Marital status } \\
\hline never married & 46 & 18 & $2.19(1.13,4.21)$ & $1.77(0.72,4.37)$ \\
\hline ever married & 62 & 53 & 1.00 & 1.00 \\
\hline \multicolumn{5}{|c|}{ Monthly income } \\
\hline Low & 46 & 18 & $0.23(0.11,0.47)$ & $0.34(0.15,0.77)^{*}$ \\
\hline High & 62 & 53 & 1.00 & 1.00 \\
\hline \multicolumn{5}{|c|}{ computer training } \\
\hline Trained & 56 & 22 & $2.40(1.28,4.50)$ & $1.88(0.92,3.87)$ \\
\hline Not & 52 & 49 & 1.00 & 1.00 \\
\hline
\end{tabular}

* Indicates significant at $p<0.05$. 
Table 5 Factors associated with adequate computer utilization among health workers at Addis Ababa administrative hospitals Ethiopia, June 2010

\begin{tabular}{|c|c|c|c|c|}
\hline \multirow[t]{2}{*}{ Predictor variable } & \multicolumn{2}{|c|}{ Utilization } & \multirow[b]{2}{*}{ COR $(95 \% \mathrm{Cl})$} & \multirow[t]{2}{*}{ AOR $(95 \% \mathrm{Cl})$} \\
\hline & Adequate & Inadequate & & \\
\hline \multicolumn{5}{|l|}{ Sex } \\
\hline Male & 26 & 88 & $3.201(1.53,6.68)$ & $3.06(1.13,8.27)^{*}$ \\
\hline Female & 12 & 130 & 1.00 & 1.00 \\
\hline \multicolumn{5}{|l|}{ Age } \\
\hline$\leq 25$ & 5 & 50 & $0.54(0.19,1.52)$ & $2.30(0.69,7.70)$ \\
\hline $26-29$ & 13 & 60 & $1.17(0.54,2.52)$ & $2.81(0.99,7.97)$ \\
\hline$\geq 30$ & 20 & 108 & 1.00 & 1.00 \\
\hline \multicolumn{5}{|l|}{ Monthly income } \\
\hline Low & 4 & 159 & $0.05(0.02,0.17)$ & $0.18(0.05,0.71)^{*}$ \\
\hline High & 34 & 59 & 1.00 & 1.00 \\
\hline \multicolumn{5}{|l|}{ Job satisfaction } \\
\hline very satisfied & 8 & 34 & $2.80(0.94,8.30)$ & $1.98(0.59,6.67)$ \\
\hline Satisfied & 23 & 101 & $2.70(1.10,6.61)$ & $3.41(1.08,10.76)^{*}$ \\
\hline Unsatisfied & 7 & 83 & 1.00 & 1.00 \\
\hline \multicolumn{5}{|l|}{ Field of study } \\
\hline$M D \& H O$ & 20 & 16 & $4.46(1.54,12.95)$ & $1.59(0.28,9.02)$ \\
\hline Nurses & 5 & 130 & $0.137(0.40,0.47)$ & $0.18(0.42,0.80)^{*}$ \\
\hline laboratory \& pharmacy & 6 & 47 & $0.46(0.14,1.50)$ & $0.89(0.23,3.40)$ \\
\hline Others & 7 & 25 & 1.00 & 1.00 \\
\hline \multicolumn{5}{|l|}{ Level of education } \\
\hline Above BSc & 17 & 11 & $15.23(6.31,36.78)$ & $0.93(0.18,4.96)$ \\
\hline BSc and below & 21 & 207 & 1.00 & 1.00 \\
\hline \multicolumn{5}{|l|}{ owned computer } \\
\hline Owned & 25 & 38 & $9.11(4.28,19.40)$ & $7.19(2.59,19.99)^{*}$ \\
\hline not & 13 & 180 & 1.00 & 1.00 \\
\hline
\end{tabular}

MD Medical doctor; $H O$ Health officer, \& others include environmental health, dentistry, physiotherapy \& radiography.

* Indicates significant at $p$-value $<0.05$.

Table 6 Factors associated with fair computer utilization among health workers at Addis Ababa administrative hospitals Ethiopia, June 2010

\begin{tabular}{lllll}
\hline Predictor variables & \multicolumn{2}{c}{ Utilization } & COR (95\% Cl) & AOR (95\% Cl) \\
\cline { 2 - 4 } & Fair & Inadequate & & \\
\hline Age & 3 & 50 & $2.16(0.42,11.08)$ & $1.70(0.30,9.74)$ \\
$\leq 25$ & 8 & 60 & $4.800(1.23,18.78)$ & $4.09(0.95,17.65)$ \\
$26-29$ & 3 & 108 & 1.00 & 1.00 \\
$\geq 30$ & & & & $0.206(0.206,0.640)$ \\
Monthly income & 5 & 159 & 1.00 & 1.00 \\
Low & 9 & 59 & & \\
High & 9 & &
\end{tabular}

MD Medical doctors, $H O$ Health officer, AOR Adjusted odds ratio, $\mathrm{Cl}$ Confidence interval.

* Indicates significance at $\mathrm{p}<0.05$. 
Among the socio-demographic variables; marital status, average monthly income and job satisfaction had statistically significant association with adequate computer knowledge. On top of this, computer training and Own Computer possessions were also statistically significant with adequate computer knowledge. On the other hand Age and Average Monthly Income had significant association with fair computer knowledge.

Those never married were more likely to have adequate knowledge on computer than ever married. This is inconsistent with the findings of a previous study from Nigeria [6] which may be due to differences in the study designs. Health workers with less average monthly income were less likely to have adequate knowledge of computer. On the other hand satisfied participants were more likely to have adequate knowledge of computer. These might be associated with the ability to afford the trainings and exposure to computers. On top of this, participants who had had computer training were more likely to had adequate computer knowledge than those who did not train. This is a logical finding that training should bring knowledge change on the trainee side. Similarly participants who had their own computer were more likely to had adequate knowledge than who had not own computer. This is also true or consistently in line with the saying that "innovation can be adopted after having knowledge about the innovation to be adopted".

On the other hand sex, age, professional variability and levels of education were not statistically significant with adequate computer knowledge of the study participants. This study was consistent with a similar study conducted in Nigeria [6]. But a study in India showed that age had significant association with computer knowledge [10].

Only few of the study participants reported adequate and fair computer utilization in this study. This finding was similar with a study conducted in India [10]. On the other hand, it was very low when compared to other studies carried out in different places [6,13-15]. This could be because of difference in economic status and the rate of diffusion of information technology among the study setups.

In this study sex, average monthly income, job satisfaction and professional background had significant statistical association with computer utilization. Additionally possession of own computer was also statistically significant with computer utilization. Only Average Monthly Income had significant association with both adequate and fair computer utilization.

In this particular study, males were more likely to use computers adequately than females. This might be due to fewer females with personal computers; accessibility of computer may differ in the place of work due to the position held by majority of women. Those health workers with low average monthly income were less likely to adequately utilized computer. Whereas satisfied study participants with their work were more likely to utilize computer than unsatisfied participants and this may be attributed to purchasing power and factors of motivation in the work places.

Regarding the professional background, nurses were less likely to adequately utilized computer. Possible explanation could be due to the work load of nurses compared to their contemporaries. Ownership of computer increases the likelihood of utilizing computer which might be associated with physical accessibility and familiarity with the technology. On the other hand age, marital status, levels of education and computer training were not statistically significant with the computer utilization habit of the study participants. This finding was similar to other studies $[6,11]$. It may be also similarity of study participants in some of their background characteristics. In this study, actual computer competence and attitude towards computer use was not measured and in some of the categories the sample size was small and this might have resulted in imprecise estimation in the computers utilization measurement. The validity and reliability of the instrument was not checked in this particular population.

\section{Conclusions}

Computer knowledge and utilization habit of health workers were found to be very low. Generally, increasing accessibility of computers and delivering trainings on computers for health workers increases knowledge and utilization of computers or increases the rate of diffusion of the technology for the health sector. Hence, programs targeted at enhancing knowledge and skill of computer use and increasing access to computer should be designed. The ministry of education should enhance computer literacy for health professionals training. The ministry of health needs to design in-service trainings on computer skills. There should be an observational study on the skill of health workers on computer use. The association between computer knowledge/skill and health care delivery competence should be studied with rigorous study designs.

\section{Competing interests}

The authors declare that they have no competing interests.

\section{Authors' contributions}

EM, GA and SM designed the study, analyzed the data and drafted the manuscript. EG was involved in analysis of the data and critically reviewed the article. All authors read and approved the final manuscript.

\section{Acknowledgment}

We would like to forward our gratitude to University of Gondar, college of medicine and health science school of public health. We thank also the supervisors, data collectors and respondents. We appreciate the cooperation from Addis Ababa health bureau. Special gratitude is extended to Dr. Tesfay Ali, Dr. Miruk Assefa and Kebir Ahmed. 


\section{Author details}

${ }^{1}$ Samara University, Samara, Ethiopia. ${ }^{2}$ School of Public Health, College of Medicine and Health Sciences, University of Gondar, Gondar, Ethiopia. ${ }^{3}$ Department of Health Education and Behavioral Sciences, Jimma University, Jimma, Ethiopia.

Received: 3 October 2012 Accepted: 15 March 2013

Published: 20 March 2013

\section{References}

1. EICTDA (Ethiopian ICT Development Agency): ICT Assisted Development Project Monitoring and Evaluation Report on ICT Laws Enacted and ICT Business Status in Major Towns of Ethiopia. Addis Ababa: ElCTDA; 2007.

2. Hofmann B: Is there a technological imperative in health care? Int J Tech Assess Health Care 2002, 18:675-689.

3. International Telecommunication Union: E-health, 2007. http://www.tu.int/ ITU-D/cyb/app/docs/e-Health_prefinal_15092008.pdf accessed on June, 26/2010.

4. Mulat D, Tadesse B: A report on ICT penetration and usage in Ethiopia. Addis Ababa, Ethiopia: Addis Ababa University; 2002.

5. Butali A, Adeyemo L, Akinshipo A, Fashina A, Savage K: Use of information and communication technology among dental students and registrars at the faculty of dental sciences, university of Lagos Nigerian. $J$ Clin Pract 2011, 14:467-472

6. Ibrahim S, Fatiu A, Abubakr A: Knowledge and utilization of information technology among health care professionals and students. J Med Internet Res 2004, 6:e45.

7. Nkeiruka A, Kene T, Emmanuel A: Computer knowledge amongst clinical year medical students in a resource poor setting. Afr Health Sci 2008, 8:40-43.

8. ICT infrastructure in Amhara region in April 2004. http://www.amhcbb.gov.et/ docs/ICTSurveySummary.pdf Accessed on February, 25, 2010.

9. Randy D, William M, Charles P: Development and initial validation of an instrument to measure physicians' use of knowledge about, and attitudes toward computers. J Am Med Inform Assoc 1998, 5:164-176.

10. Raja $E$, Mahal $R$, Masih V: An exploratory study to assess the computer knowledge, attitude and skill among nurses in health care setting of a selected hospital, Ludhiana, Punjab, India. Online J Nurs Inform 2004, 8:1304-1307.

11. Samuel S: Kensington: allied health professionals' use of online evidence. Int J Med informatics 2004, 73:391-401.

12. Federal Democratic Republic of Ethiopia, Population Census Commission: Summary and statistical report of the 2007 population and housing census results. Addis Ababa, Ethiopia; 2008.

13. Yaghmaie $F$, Javasuriva R, Rawstorne P: Computer experience and computer attitude. Stud Health Technol Inform 1998, 52:895-899.

14. Roger F, Behets $\mathrm{M}$, Andre J: A survey of medical informatics. Belgium Med Inform 1987, 12:249-262.

15. Bennie E, Harsanyi B: Attitudes towards computer technology between nursing and medical educators. Texas, USA: Texas Tech University; 1988.

\section{Submit your next manuscript to BioMed Central and take full advantage of:}

- Convenient online submission

- Thorough peer review

- No space constraints or color figure charges

- Immediate publication on acceptance

- Inclusion in PubMed, CAS, Scopus and Google Scholar

- Research which is freely available for redistribution 